\title{
COMENTARIO AL TEXTO \\ DE JOSÉ ESPERICUETA: "FUKÚ AND THE \\ POST-COLONIAL LEGACY \\ OF THE WEST IN THE \\ BRIEF WOUNDROUS \\ LIFE OF OSCAR WAO" \\ José Manuel Orozco Garibay*
}

La simple idea de la tragedia y la violencia en el origen de las plagas contra la familia Cabral de León narradas por Juniot Díaz da lugar a algunas preguntas: ¿qué es fukú? ¿A qué se refiere el fukú americano? ¿Acaso tanto la violencia como la tragedia afectan la vida de esa familia (todos sus miembros padecen la maldición del fukú)? ¿Constituye la historia de una nación, la llamada República Dominicana?

La idea detrás del texto es que identificar problemas generales no resulta una manera adecuada de lidiar con los problemas personales. Se vinculan a los problemas de una nación, eso sí. Aún más, hay un problema que tiene que ver con la inmigración a Estados Unidos, de manera que la maldición afecta a personas, naciones e inmigrantes, y lo hace de tal manera que Óscar Wao sufrirá las consecuencias de haber nacido en la República Dominicana, de haberse ido a Estados Unidos a los tres años y de haber vuelto a la República Dominicana en busca de un sentido para su vida.

La maldición que afecta a la isla persigue a Óscar a lo largo de su vida: no puede conseguir el afecto de las mujeres por su obesidad (cuando de niño era un seductor), es un nerd que lee ciencia ficción - de la que sabe todo pero casi nadie se interesa en eso que lee- y

* Departamento Académico de Estudios Generales, ITAM. 
va al colegio sin lograr adaptarse al estilo de vida estadounidense. Así, después de regresar a la República Dominicana encuentra su destino: se enamora de una prostituta que se casa con un capitán cercano al dictador Trujillo, de modo que es golpeado brutalmente por el guardaespaldas del dictador. Vuelve a Estados Unidos y busca a Ybón en la Dominicana, donde finalmente encuentra la muerte (a manos de los guardaespaldas de Trujillo).

De la misma forma que Óscar, su madre, Belicia, sufre la maldición. Quedó huérfana muy pronto y pasó de una familia a otra, como mesera o sirvienta. De pronto, tal como le ocurrió después a su hijo, Belicia conoce a el Gánster, que le ofrece una buena vida; y en efecto, vive bien hasta que el Gánster se casa con la hermana del dictador Trujillo. La golpean y tiene que partir hacia Nueva Jersey con su green card de refugiada.

Lola es la hermana de Óscar y lleva una vida mejor. Es educada por la mamá de Belicia, la Inca, cuyas historias sobre la familia hacen pedazos la idea que tenía Lola de Belicia. Su destino es sufrir a partir de los dolores de su familia.

La Inca tiene poderes especiales. Ve a un hombre sin rostro, una

102 presencia, un fantasma, que se presenta cuando Abelardo, su marido, está por morir. Abelardo manotea para que la Inca deje de hablar sobre sus ideas extrañas, pero ella enciende velas hacia la entrada y el camino que conduce a la casa. Abelardo también ha sufrido la maldición de Trujillo, que lo encarceló y mandó golpear.

A pesar de todas las maldiciones y destinos que afectan a los miembros de la familia, Óscar dice algo grandioso antes del fin de su vida: “¡La belleza, la belleza!", pues descubre que más allá de la intimidad sexual, la conversación y los pequeños detalles que ha vivido con Ybón convierten la existencia de todos en algo mejor. Abre el camino a la posible solución de la maldición (zafa del fukú): la cura a través de la mejoría, el esfuerzo, el amor, de suerte que es preciso enfrentar la maldición. 


\section{Primera idea filosófica}

Hay una maldición que es como una plaga que azota a toda una familia, que procede de la plaga que afecta al país. El resultado tanto del poscolonialismo como del imperialismo estadounidense es la maldición, que será la obsesión de familias, individuos, sociedades, ya que es el resultado de la conquista, el colonialismo y el imperialismo.

\section{Consecuencias}

La República Dominicana tiene la maldición de la violencia, la tragedia y la mala fortuna, que afecta tanto a los individuos como a toda la nación. La violencia encarna en Trujillo, el más infame dictador que la isla haya tenido que llorar. Trujillo solía, por ejemplo, ponerle su nombre a cuanto lugar se le ocurría, robaba tierras que le gustaban incluso a costa de sus amigos (y los mataba si se oponían) y contaba con un sistema de vigilancia que funcionaba a la perfección. Era como un dios, él mismo. Por ello, Wao escribe algunos ensayos (que en la novela están perdidos), tratando de explicar la cura de acuerdo con la fantasía de superación, dado que ya había vencido una golpiza. De todos modos, muere a manos de Trujillo pero dice en sus ensayos que volverá de la muerte para vengarse como superhéroe de Trujillo y su gente. Sería un vengador del futuro.

Es claro que la tradición tiene que ver con una representación identitaria del propio origen. Se entrecruza con la historia de una nación y sus maldiciones poscoloniales e imperiales. Por otro lado, está el conflicto de ser un inmigrante en Estados Unidos y sentirse fuera de lugar en ese país. Así - dice Espericueta-, "enseñar literatura latinoamericana a estudiantes americanos, especialmente del tipo que se comenta, plantea el problema de hacer que los estudiantes comprendan las tradiciones latinas". Por eso Juniot Díaz, el narrador, escribe notas al pie de página para aclarar quién fue Trujillo y la esencia de la maldición.

En México podemos hablar de la tradición de Quetzalcóatl, el Dios redentor. Comprende por igual el complejo de los mexicanos de haber 
sido conquistados, la incapacidad de formar un país exitoso y vivir en la pobreza, la violencia, el resentimiento y un sentimiento de soledad. La idea de ser una nación incapaz de alcanzar nada en el teatro de las grandes naciones, de ser un país de migrantes perseguidos en todo tiempo. Estos elementos proporcionan una clave para entender nuestra identidad con el resto de Latinoamérica. Espericueta sostiene que las maldiciones personales están interconectadas con las maldiciones nacionales, más la inmigración. El entendimiento entre las culturas latinas y la estadounidense resulta casi imposible. Con todo, podemos alcanzar ese objetivo, literariamente, si combinamos la comedia con la ciencia ficción, la novela con la historia, y elaboramos relatos diversos. Una narrativa que permita que la gente alcance dos objetivos: primero, entender quiénes somos, y segundo, hacer posible que escapemos de las maldiciones. Así tendremos una identidad.

Para regresar al fukú de Wao, a la maldición, ¿podemos hablar de un fukú estadounidense? ¿Hay una cura, zafa, del fukú? ¿Es posible que la idea de ser fuerte (como un superhéroe), de haberse superado y de experimentar la belleza, puedan servir para superar el fukú? En otras palabras, ¿podemos escapar a nuestro destino? ¿Podemos tener una identidad capaz de enfrentar la identidad estadounidense? Antes de responder, Espericueta explica la maldición del fukú:

Así, la nota cuestiona la historia familiar. Además, la reconstrucción de Yunior de los sucesos de la novela está ligada a su propia incertidumbre. Como dice Mónica Hanna, "al recalcar la naturaleza artificial de todas las historias, la narrativa obliga al lector a examinar las estructuras de poder detrás del acto de narrar". ${ }^{1}$ Yunior finge que acepta ese inicio que no prefiere, pero establece una tenue coexistencia de las dos narrativas: la primera, comienza cuando un joven doctor llamado Abelardo se niega a entregar a su bella hija al dictador del país. Abelardo es arrestado y torturado, y pasa el resto de sus días mentalmente incapacitado en una de las peores cárceles del país.

${ }^{1}$ Monica Hanna, “"Reassembling the fragments': Battling historiographies, Caribbean discourse, and nerd genres in Junot Díaz's The brief wondrous life of Oscar Wao", Callaloo, 33.2, primavera de 2010, pp. 498-520. 
La segunda se refiere a una plaga que trajo Cristóbal Colón.

Decían que había venido de África, en los gritos de los esclavos; que era la maldición mortal de los taínos, lanzada cuando un mundo pereció y comenzó otro; que era un demonio traído al mundo por una puerta de pesadilla que se abrió en las Antillas. Fukú americanus, o más coloquialmente, fukú: una maldición o una condenación, y específicamente, la maldición y la condenación del Nuevo Mundo. Se llama también fukú del Almirante, porque el Almirante fue su partera y una de sus grandes víctimas europeas. Aunque “descubrió” el Nuevo Mundo, el Almirante murió miserable y sifilítico, escuchando (dizque) voces divinas. En Santo Domingo, la tierra que más amó [...] el nombre mismo del Almirante ha llegado a ser sinónimo de ambas clases de fukú, la pequeña y la grande. Decir su nombre en voz alta o incluso oírlo es atraer la calamidad sobre la cabeza de uno y de sus seres queridos. [p. 1].

Trujillo fue un hombre apasionado. Estuvo involucrado con Kim Novak y con la madre de Ramfis, así que la maldición pudo haber llegado a la familia Kennedy. Antes de que Abelardo - en la novelapudiera ver el bombardeo de Estados Unidos sobre Hiroshima y Nagasaki, dos días después de esa visión, Socorro (la esposa de Abelardo) soñó que el hombre sin rostro estaba parado junto a la cama de su marido. Podemos entonces pensar en un fukú americanus. Puede ser que, de cualquier manera, el fukú pasara a Estados Unidos a través de Trujillo. Esa es la razón del declive del imperio, su pobreza, sus problemas económicos, la parálisis política, etc. Esto significa tratar de entender que en nuestra representación de una tradición humana, algunas de las tribulaciones latinoamericanas pueden pasar a Estados Unidos, ya que inmigrantes, políticos, conexiones, mezclan las culturas. ¿Por qué no?, podemos pensar inclusive en el traspaso de maldiciones y destinos de una cultura a otra. En la medida en que somos 40 millones de hispanos en Estados Unidos, y la cifra aumenta, nuestro pasado poscolonial y posimperial penetran en el modo de vida estadounidense (para no mencionar el problema de la negritud). 


\section{Respuesta a algunas cuestiones. Segunda idea filosófica}

Se asume que la identidad no es una experiencia personal independientemente de la historia de una nación donde una persona vive. Todas las maldiciones, destinos y mitos que acompañan a las tradiciones dejan su marca. Debemos entender la identidad como la combinación de esos tres elementos. También es verdad que hasta donde sabemos, las tradiciones tienen que ver con patrones de creencias que se repiten generación tras generación. Como en Cien años de soledad, de García Márquez, la soledad pasa de generaciones en generaciones hasta el fin de los tiempos. De la misma forma ocurre en la República Dominicana, donde la maldición pasa de Abelardo a Belicia y a Óscar mediando Lola. Ha de comprenderse también que los inmigrantes de Estados Unidos pasaron rápidamente del tercer al primer mundo. El resultado es la incapacidad para adaptarse a las demandas de la vida en un nuevo sistema de reglas, lo que también plantea dificultades para el país receptor, que debe acomodarse a los valores que provienen de afuera. La naturaleza de esa mutua asimilación se explica si imaginamos el dilema de Óscar. El platanero Óscar aprende en la escuela inglés e historia de Estados Unidos y lee ciencia ficción. Ve películas en las que salen super-

106 héroes y todo eso se relata en medios modernos de comunicación. Pero al mismo tiempo, Óscar tiene un pasado arraigado en la República Dominicana, con su pobreza, dictadura, inequidad y el conjunto de ideas supersticiosas. Así, por ejemplo, la idea de un dios omnipresente como Trujillo podría asociarse a Dark Vader o a un extranjero como Óscar mismo. De hecho, los inmigrantes son llamados “alienígenas": la alienación tiene que ver con algún extraño que nunca se integra al sistema de creencias. Un lado de la persona se identifica con los modelos estadounidenses, pero el otro busca sus orígenes. Esta dicotomía es el dilema de la identidad.

La cuestión de la diferencia entre el fukú americano y fukú americanus nos indica que el origen del fukú es tanto la violencia de Cristóbal Colón como la tragedia de su vida. Colón representa esa violencia porque así fue como entró en la Isla Cero, la República Dominicana, la Española, que fue la tierra de Colón, y que prefería como la mejor de 
las tierras. Empero, la maldición de esa violencia acompañó al Almirante hasta su muerte.

Deberíamos hablar de un fukú americano en el sentido de que debería de ser el caso de que muchas tragedias y violencia en América son producto de la maldición, y provienen de una suerte de destino o condenación. La incapacidad de comunicación con otros, como en el amor, es clara cuando apreciamos el modo cómo rechaza y anula el imperialismo estadounidense. Los estadounidenses en general no saben cómo comunicarse con los latinoamericanos, para no hablar de países de África y el Medio Oriente. Por esa razón, podemos ver que el fukú está también en Estados Unidos. Como se dijo, Trujillo tuvo relaciones con estadounidenses. Relaciones estrechas de amor y ternura con Kim Novak, que pudo haber sido el canal para pasar la maldición hasta los Kennedy, por eso es que el fukú es un fukú americanus.

En la literatura, tenemos en las manos una novela con varios niveles de lenguaje posmoderno. Primero, se encuentra el texto en sí mismo: cuenta la historia de la familia Cabral de León. Segundo, tenemos la historia de cada uno, Óscar, Belicia, Ybón, Lola, la Inca (comenzando con Abelardo), bajo la espinosa sombrilla de Trujillo. Tercero, tenemos los pies de página de Junot Díaz, en los que se reconstruye el texto base sin modificar la estructura, con el propósito de que el lector entienda el contexto dominicano. Cuarto, tenemos la historia de la República Dominicana y la inmigración a Estados Unidos, con todas sus dimensiones de intercambios culturales y modificaciones. Quinto, el lenguaje en sí mismo que usa Díaz valiéndose de palabras tanto en inglés como en español en un ritmo de poesía, siguiendo el ejemplo de Espericueta:

[F]rom the richest jabao in Mao to the poorest güey in el Buey, from the oldest anciano sanmarcosiano to the littlest carajito in San Francisco.

Es como una pintura en la que las inscripciones producen una clase de lenguaje nuevo (¿acaso no evolucionan los lenguajes?). Todos esos niveles están interrelacionados. Así, usamos la comedia cuando podemos reír a causa del nerd de Óscar con sus problemas con las mujeres; pero, al mismo tiempo, hay una tragedia, ya que Óscar morirá amando a una prostituta decadente que será capaz de proporcionarle un senti- 
do de la belleza. Una prostituta tiene que hacer sexo, cobra por sexo. Pero Ybón da amor con un toque fino de sentimiento estético. Hay horror en la imagen del hombre sin rostro. Y hay ciencia ficción bajo la idea de una recuperación de la maldición, ya que Óscar escribe sus ensayos sobre el ADN cósmico con el objeto de vengar a los dominicanos de Trujillo y sus guardaespaldas después de muerto. Finalmente, tenemos que hacer historiografía de la República Dominicana para comprender el estrés poscolonial y las consecuencias del imperialismo. Es necesario conocer la historia de Estados Unidos. Todos estos géneros se mezclan con el objeto de expresar los múltiples problemas de la identidad y de la humanidad en una forma local, aunque universal. Dice Espericueta:

Lo que es particularmente único y refrescante en la novela de Díaz (e instructivo al examinar esta pieza literaria muy contemporánea) es la libertad con la que se acerca a las tradiciones occidentales. El elemento de integración que es común en su obra (géneros, la interconexión de historias, pueblos) se aprecia con más claridad en la aproximación de Díaz a los tropos y tradiciones literarias por excelencia. Sobre las ambigüedades del fukú y su contrahechizo la zafa, Yunior escribe: "antes era más popular, más grande, por decirlo así, en Macondo que en McOndo" (p. 7). Aunque Macondo se asocia (con justa razón) con García Márquez y las generaciones anteriores, Díaz lo acoge aquí. El fukú se presenta como realidad y, potencialmente, superstición. Óscar Wao es a la vez Macondo y McOndo, realismo mágico, ciencia ficción e historia posmoderna todo en uno. Otro tanto ocurre cuando se trata de religión. Cuando la Inca reza por Beli en el momento de su golpiza, Yunior se mete en la narración para anunciar:

Este parágrafo merece deconstrucción. Dice que podemos tener integración cuando la interconexión entre la gente está garantizada. Sin embargo, hablamos con un estadounidense en Florida sin sentir que nos acepta, que estamos integrados allí. Unas semanas antes, en Orlando, al bajar por café a la recepción el intento por hablar con la recepcionista de color resultó infructuoso. Eso a pesar del buen inglés que yo, como latino, era capaz de manejar. En otras ocasiones traté de sostener una conversación con otras personas en los parques de Disney, pero nadie 
escuchaba. ¿Por qué? Es así debido a que la integración significa algo más que una mera interconexión. Significa vivir, compartir el lenguaje, usar el argot, tener historias en común. Si uno lo consigue, entonces puede pasar que haya integración. Supongamos, empero, una mera aproximación lingüística. La novela cruza historias, narra interacciones, describe procesos de interacción y de conexión, así que de alguna manera Óscar, Belicia, Lola, están integrados con el ADN cósmico estadounidense y el ADN cósmico dominicano, de tal suerte que hay una red de relaciones de sustentación. El patrón de entrecruzamientos está dado, y nosotros solamente tenemos que descubrir los rasgos, los caminos, los movimientos. Por otro lado, Espericueta dice que fukú y zafa van de la mano, así que tanto los tropos como las tradiciones se mezclan a la perfección. Las tradiciones del fukú mágico tienen su antídoto en la zafa. La cuestión de si algo es mágico o no da lugar a la razón. Sin embargo, es un nuevo tipo de razón que combina la magia con la realidad. Óscar representa la síntesis de Macondo y McOndo, ya que es parte de un realismo como el que nos cuenta Gabriel García Márquez $\mathrm{y}$, al mismo tiempo, como un inmigrante integrado, usa su Mac para escribir sus cosas, usa iPhone e IPod. El camino entre Macondo y McOndo se cruza en un hombre posmoderno que vive en Estados Unidos. Su identidad es un rompecabezas. ¿Podemos vivir de esa manera? ¿Cómo ordenamos esos diversos niveles de realidad en una sola vida singular? La respuesta es delirante, porque si vemos que la maldición no podría evitarse (Óscar muere diciendo “¡La belleza, la belleza!”, a manos de los guardaespaldas de Trujillo en la República Dominicana a la que había vuelto por su amor), parece ser que la vida singular combina el realismo mágico con la ciencia ficción y la historia posmoderna de modo fallido.

\section{Conclusión de Espericueta}

Díaz no se restringe al abrazar las tradiciones (y herencias) a las que pertenece. Su novela es un ejemplo de un bricoleur inmigrante multicultural y un retrato global de la interconexión (social y política). Su valor contemporáneo radica en su habilidad para obligar al lector a lidiar con la 
alienación de una realidad particular incluso cuando lo invita a aceptar la naturaleza compartida de esta realidad.

La novela es como un espejo que refleja algo universal. El asunto aquí es el carácter de los inmigrantes como retrato de muchas realidades de su vida, la mágica, la posmoderna, la del fukú (que se incardina en los destinos de las tradiciones). El resultado es un lenguaje que permite ver, sentir y entender el arcoíris de seres que coexisten en una persona singular que es tanto particular como universal, pues comparte con los otros ese complejo proceso de la identidad en la inmigración. Enfrenta la conquista, la dictadura, el imperialismo, y es capaz de ver a fondo con el objeto de alcanzar un punto de responsabilidad con el fin de resolver los problemas de saber vivir con las características de ese ser bricoleur. Esas características tienen cierto optimismo, se mueven adelante en conexión con el amor, como dice Espericueta.

\section{Todos somos hombres $\mathrm{X}$}

Habiendo dicho lo anterior, es claro que todos tenemos problemas de identidad. Eso no quiere decir que todos tengamos problemas de extrañamiento o enajenación. Seamos inmigrantes o no, tenemos que aceptar un conjunto de elementos que constituyen nuestros infiernos personales. Primero, todos venimos de una familia. Todos hemos heredado las "maldiciones" de la familia de la que provenimos. Al mismo tiempo, todos tenemos una biografía y tendemos a contar la historia de nuestra vida según el modo en que describimos nuestra existencia en el contexto de los meros problemas de la vida. Es parte de nuestra confusión aceptar la neurosis de nuestra vida. Somos parte de un país con neurosis y maldiciones. Por supuesto, algunas veces ocultamos nuestro lado oscuro y preferimos mostrar nuestro lado brillante. Sin embargo, si sumamos la serie de factores, tenemos familia, autobiografía, contexto y país. Todos los destinos y las maldiciones que vienen con esa suma de factores producen un sufrimiento que debemos enfrentar. Ser un 
hombre X significa también que nosotros, como latinoamericanos, vivimos de acuerdo con los modernos McOndo de la tecnología, mezclados con tradiciones y convenciones que vienen de nuestros ancestros. En nuestra cultura llevamos a cuestas la maldición de la Conquista y el trauma poscolonial. Es algo que disminuye nuestro ser mismo. Se trata de algo problemático cuando analizamos el choque entre clases, grupos, identidad, que se fragmentan sin alcanzar una síntesis. La cultura criolla se separa de los mestizos y los indios. La manera de capturar una esencia de la identidad mexicana es equivalente a la manera en que hablamos de nosotros mismos como seres alienados de nuestro ser.

Al tratar de la emigración, debemos admitir los nuevos problemas. Primero, los emigrantes deberían adaptarse a la nación a la que van. Segundo, los emigrantes conservan por lo común sus tradiciones mezcladas de formas modernas y posmodernas de nuestras sociedades. Tercero, viven con nostalgia; sin embargo, al mismo tiempo, tratan de olvidar todo lo que dejaron para poder entrar en su nueva vida, aunque sin éxito. Una maldición consistente en estar rotos e incompletos los acosará toda la vida. Como resultado, al igual que el destino de Óscar Wao, debemos comprender el patrón de creencias con las que nos identificamos, $\mathrm{y}$, al mismo tiempo, un conjunto de nuevas creencias en permanente transformación. Algunos emigrantes regresarán a la muerte; otros buscarán sus raíces. Las oposiciones son claras: tradición contra modernidad, vida colectiva contra vida individual, contexto contra localismo, origen y propósito. Las tensiones son evidentes.

Somos producto de una conquista violenta. Vivimos procesos violentos de adaptación. Estamos aislados, como accidentes respecto de la sustancia. Nos reímos de nosotros mismos, buscamos expresarnos en las obras de arte. Es la crisis que podemos inferir del texto de José Espericueta. O somos inmigrantes (que es lo peor) o no (que es lo triste). 
CITAM Derechos Reservados.

La reproducción total o parcial de este artículo se podrá hacer si el ITAM otorga la autorización previamente por escrito. 